\title{
Chapter 17 \\ The Corrosion Behavior of High-Alloy \\ CrMnNi Steels-A Research Work \\ on Electrochemical Degradation in Salt- and Acid-Containing Environments
}

\author{
Marcel Mandel, Volodymyr Kietov and Lutz Krüger
}

\begin{abstract}
The electrochemical corrosion behavior of high-alloy cast steels as well as of steel/ceramic composites was analyzed by conventional polarization, electrochemical impedance and long term-outdoor exposure tests in sulfuric acid and chloride containing solutions. Additionally, for the determination of corrosion initiation processes and its subsequent implications, potentiodynamic polarization and electrochemical noise were combined with the acoustic emission technique. The results of these studies show that several corrosion mechanisms occur simultaneously when the surface is potentiodynamically stressed, and that pitting corrosion starts with a specific time-shift to its initiation at the surface.
\end{abstract}

\subsection{Introduction}

A wide range of techniques and analysis tools have been developed for studying the electrochemical corrosion behavior of high-alloy steels, with such techniques providing detailed information about the specific characteristics of steels in defined environments. The subsequent chapter explains how the electrochemical corrosion of high-alloy TRIP/TWIP steels with zirconium dioxide particle reinforcement was analyzed by a number of methods, such as conventional cyclic polarization, electrochemical impedance, indoor and outdoor exposure tests and special analytical tools, such as the combination of linear polarization and electrochemical noise measurement, as well as the acoustic emission method. For the presented results, the corrosion behavior of the analyzed steel and composite materials in salt- and/or acid-containing media was dictated primarily by the main alloying elements chromium, manganese and nickel as well as by the zirconia particle reinforcement. Due to the pronounced

M. Mandel $(\bowtie) \cdot$ V. Kietov $\cdot$ L. Krüger Institute of Materials Engineering, Technische Universität Bergakademie Freiberg, Gustav-Zeuner Str. 5, 09599 Freiberg, Germany

e-mail: mandel@iwt.tu-freiberg.de 
passivity, pitting and uniform corrosion were observed, which are the predominant corrosion mechanisms and the focus for the subsequent interpretation of data in the relevant media.

\subsection{The Effect of Transformation-Induced Plasticity (the TRIP Effect) on the Electrochemical Degradation of a High-Alloy CrMnNi Steel}

Due to the large number of their excellent mechanical properties, their high corrosion resistance and acceptable cost-benefit ratios, high-alloy stainless steels are commonly used in a wide range of applications. As a certain type of this material class, high-alloy TRIP steels offer further enhancement of the mechanical characteristics due to the transformation induced plasticity effect, which arises from a microstructural phase transformation of the metastable austenite phase into a martensite phase during an energy-absorbing process [1-3]. This characteristic combined with good corrosion durability facilitates their integration in the technical configuration for safety-relevant components by reducing costs for subsequent corrosion-protection measures.

With the focus on the material's corrosion behavior, a particular advantage of high-alloy steels is their good corrosion resistance and durability in most aggressive environments. This corrosion resistance is predominantly due to the formation of a chromium-enriched passive oxide layer that restrains the metal-dissolution process during corrosion attack to a technically acceptable level. A further improvement is achieved by the addition of nickel and manganese. Nickel tends to agglomerate as an interlayer at the metal/oxide interface in its metallic state and can also affect the dissolution rate of the entire steel component, whereas manganese increases the solubility of nitrogen and molybdenum, elements that significantly enhance the pitting-corrosion durability of steels [4].

The effect of plastic deformation on the pitting corrosion sensitivity of high-alloy CastX6CrMnNi16-7-3-with the composition given in Table 17.1-was analyzed in a sodium chloride solution [5].

For the evaluation, two degrees of deformation-with $\varepsilon=9 \%$ and $\varepsilon=18 \%$ were defined and the influence of plastic deformation was investigated by cyclic voltammetry before comparison with the initial state. Figure 17.1 presents the scanning electron microscopy (SEM) micrographs for the initial state and after plastic deformation of the TRIP steel, with those components identified that acted in an anodic/cathodic manner during the corrosion attack.

Table 17.1 Chemical composition of high-alloy CastX6CrMnNi16-7-3 TRIP steel in wt\%

\begin{tabular}{l|l|l|l|l|l|l|l|l|l}
\hline $\mathrm{C}$ & $\mathrm{N}$ & $\mathrm{Cr}$ & $\mathrm{Mn}$ & $\mathrm{Ni}$ & $\mathrm{Mo}$ & $\mathrm{Al}$ & $\mathrm{Ti}$ & $\mathrm{Si}$ & $\mathrm{Fe}$ \\
\hline 0.06 & 0.13 & 16.3 & 6.71 & 3.06 & 0.037 & 0.061 & 0.0023 & 0.91 & Bal. \\
\hline
\end{tabular}


In addition to the $\delta$-ferrite, which was the dominant anodic component in the initial state (Fig. 17.1a), a number of deformation bands formed inside the austenitic phase during the deformation process (Fig. 17.1b) and also served as anodic components, whereas beside the $\delta$-ferrite for $\varepsilon=18 \%$, elongated $\alpha^{\prime}$-martensite needles dictated the anodic dissolution process of the cast steel (Fig. 17.1c). The results of the polarization tests and the electron micrographs after the corrosion process are shown in Figs. 17.2 and 17.3.

The anodic polarization behavior clearly exhibited a strong dependency on the state of deformation. The initial state revealed the expected passivation and the initiation of metastable pitting corrosion when the anodic potential increased. For $\varepsilon=$ $9 \%$, the corrosion potential $E_{\mathrm{Corr}, 1}$ increased significantly, but the range of passivity was reduced. It was assumed that this effect could be attributed to the homogeneously formed and distributed micro-anodes inside the large austenite grains (Fig. 17.1b). For the highest analyzed degree of deformation of $\varepsilon=18 \%$, the corrosion potential dropped again to the level of the initial state, and no significant passivation or pitting behavior was detected. In comparison to the initial state and $\varepsilon=9 \%$, the
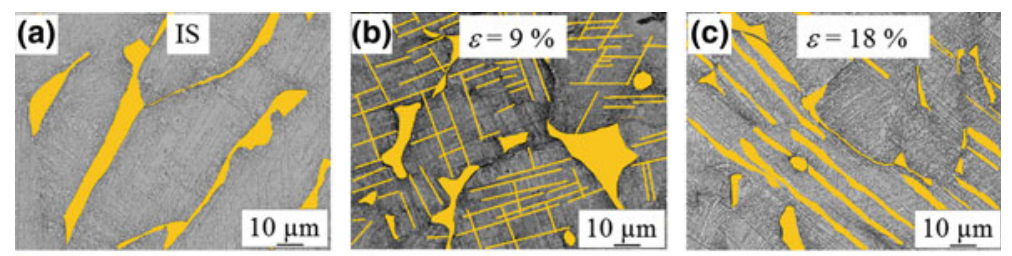

Anodic component - (a) $\delta$-ferrite, (b) $\delta$-ferrite + deformation bands

(c) $\delta$-ferrite $+\alpha^{\prime}$-martensite

Fig. 17.1 SEM micrographs of a the initial state, $\mathbf{b} \varepsilon=9 \%$ and $\mathbf{c} \varepsilon=18 \%$, and the anodically active components during a corrosion attack [5]

Fig. 17.2 Cyclic polarization curves of the high-alloy CrMnNi steel at different degrees of deformation in $5 \mathrm{wt} \%$ sodium chloride solution. $E_{\text {Corr,1-corrosion potential }}$ before polarization,

$E_{\text {Corr,2-corrosion potential }}$ after polarization. IS-initial state [5]

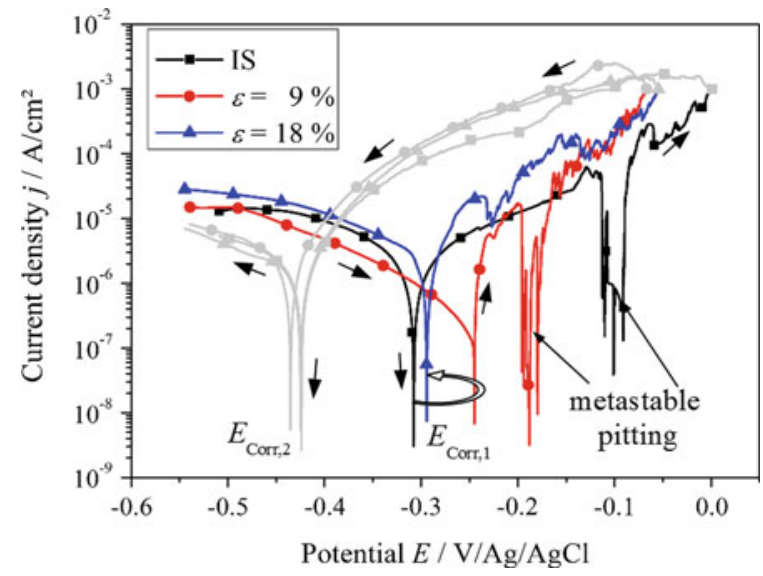



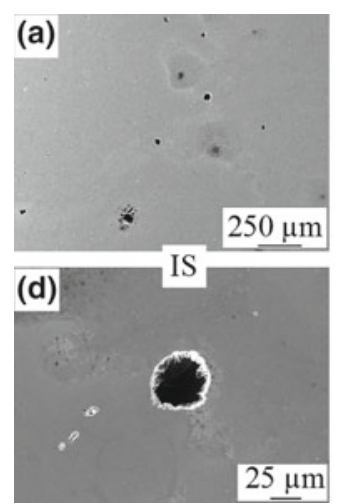
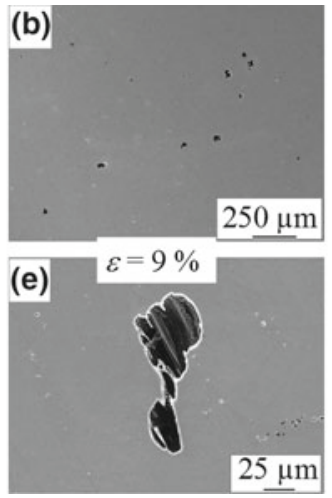
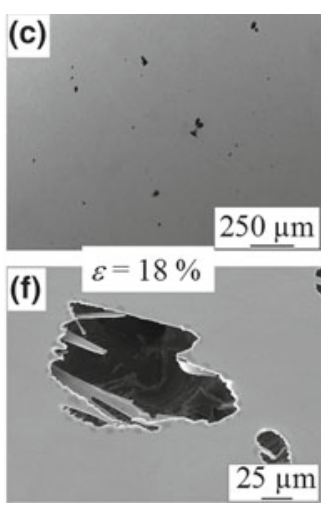

Fig. 17.3 SEM micrographs after polarization in $5 \mathrm{wt} \%$ sodium chloride solution. a Initial state. b $\varepsilon=9 \%$. c $\varepsilon=18 \%$. d, e and $\mathbf{f}$ detailed views [5]

highest degree of deformation also resulted in the highest degree of corrosion sensitivity during anodic polarization. In comparison, the reverse scan did not indicate any clear difference in polarization behavior, with all deformation states exhibiting similar curve trends and secondary corrosion potentials $E_{\mathrm{Corr}, 2}$. This characteristic clearly shows that after its initiation, the pitting corrosion attack-which was found for each state after the cyclic polarization (Fig. 17.3) — dictates the ongoing corrosion behavior of the whole steel sample and is independent of the degree of deformation.

\subsection{Influence of Particle Reinforcement on the Corrosion Behavior of a High-Alloy Steel in Sodium Chloride Solution}

The corrosion behavior of the spark plasma sintered zirconia particle-reinforced highalloy $\mathrm{X} 5 \mathrm{CrMnNi14-6-6}$ steel was investigated by potentiodynamic polarization in a sodium chloride solution [6]. The chemical compositions of the steel and zirconia powder used are given in Tables 17.2 and 17.3.

Table 17.2 Chemical composition of the high-alloy X5CrMnNi14-6-6 steel in wt\%

\begin{tabular}{l|l|l|l|l|l|l|l}
\hline $\mathrm{C}$ & $\mathrm{Cr}$ & $\mathrm{Mn}$ & $\mathrm{Ni}$ & $\mathrm{Al}$ & $\mathrm{S}$ & $\mathrm{Si}$ & $\mathrm{Fe}$ \\
\hline 0.04 & 14.02 & 6.14 & 6.11 & 0.11 & 0.02 & 0.91 & Bal. \\
\hline
\end{tabular}

Table 17.3 Chemical composition of the Mg-PSZ powder in wt \%

\begin{tabular}{l|l|l|l|l|l}
\hline $\mathrm{ZrO}_{2}$ & $\mathrm{MgO}$ & $\mathrm{HfO}_{2}$ & $\mathrm{SiO}_{2}$ & $\mathrm{Al}_{2} \mathrm{O}_{3}$ & $\mathrm{TiO}_{2}$ \\
\hline Bal. & 3.37 & 1.73 & 2.43 & 0.63 & 0.14 \\
\hline
\end{tabular}


Figure 17.4 presents the micrographs of the sintered materials without Mg-PSZ (i.e., $0 \mathrm{vol} \%$ ) and with contents of 5 and $10 \mathrm{vol} \%$. In comparison to the reinforced composites, the material without particle reinforcement exhibited an increased degree of porosity (Fig. 17.4a). For the composite materials (Fig. 17.4b, c), it was obvious that when the particle content increased, the matrix/particle interfaces also increased significantly, which drastically affected the corrosion behavior of the materials.

In Fig. 17.5 the potentiodynamic polarization curves in a $5 \mathrm{wt} \%$ sodium chloride solution are shown, while Fig. 17.6 presents the corresponding electron micrographs after corrosion of the sintered materials.

The polarization curves of the material without $(0 \mathrm{vol} \%)$ and with 5 vol\% particle content showed slight passivation, which was more pronounced for the unreinforced material than for the composite. In comparison, the composite material with 10 vol\% Mg-PSZ exhibited the lowest corrosion potential and no significant passivation behavior, which indicated a higher degree of corrosion sensitivity.

The micrographs observed after corrosion attack clearly showed the formation of corrosion pits for the materials with 0 and 5 vol\% Mg-PSZ (Fig. 17.6a, b), which was
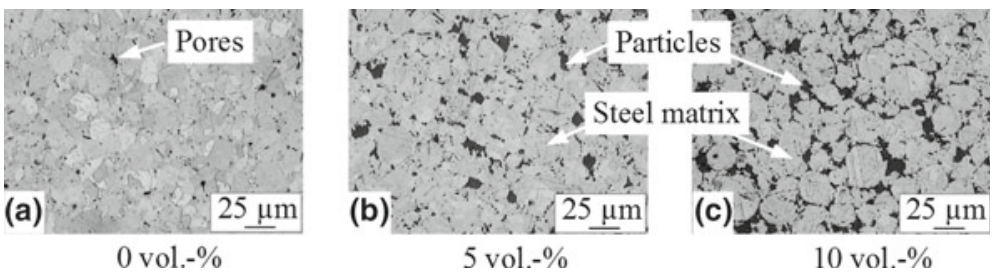

Fig. 17.4 Optical micrographs of the spark plasma sintered and Mg-PSZ particle-reinforced highalloy steel. a without (0 vol\%), b with $5 \mathrm{vol} \%$ and $\mathbf{c}$ with $10 \mathrm{vol} \%$ particle contents [6]

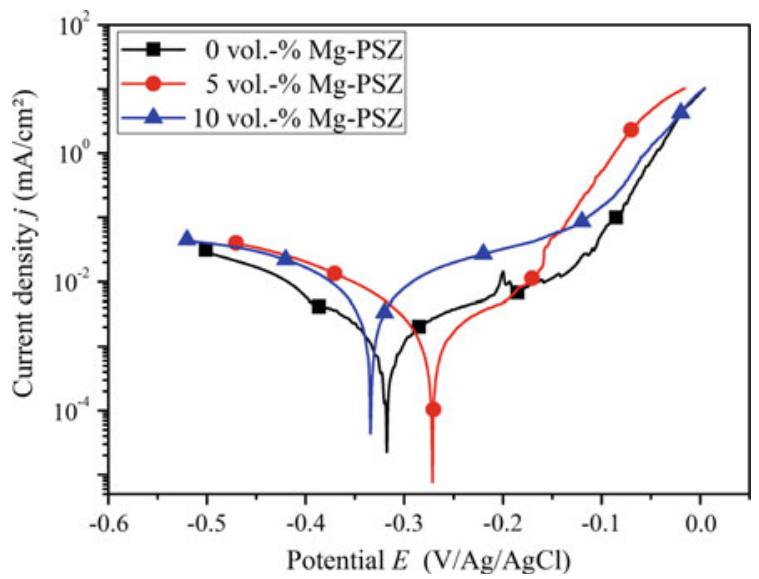

Fig. 17.5 Potentiodynamic polarization curves of the spark plasma sintered high-alloy steel with different Mg-PSZ particle contents in $5 \mathrm{wt} \%$ sodium chloride solution [6] 
in full agreement with the anodic polarization behavior identified. It was assumed that pitting was initiated at the pores for the unreinforced material, because such pores represented critical weak points in and on the surface that interrupted the formation of a dense and continuous passive oxide layer. For the composite with $5 \mathrm{vol} \% \mathrm{Mg}$-PSZ, the micrograph clearly indicated that pitting had its origin at the matrix/particle interface. For the composite with 10 vol\% Mg-PSZ, the corrosion attack was more homogeneous and no pitting was observed, with the entire surface indicating a uniform corrosion attack (Fig. 17.6c). As a primary result, the polarization curves and the micrographs clearly indicated that by increasing the Mg-PSZ particle content, the corrosion mechanism changed from pitting to general corrosion. Due to the increase in the particle content up to $10 \mathrm{vol} \%$, the formation of a dense and compact passive oxide layer was suppressed and the composite became more susceptible to corrosion. To evaluate the passive oxide destabilization, the contents of iron and the main alloying elements found in the electrolyte was analyzed by ICP-MS (Inductively Coupled Plasma Mass Spectrometry) after the polarization. The results are presented in Fig. 17.7.

The comparison clearly shows that significant increases in the contents of iron, chromium, nickel and manganese are detectable in the solution when the Mg-PSZ

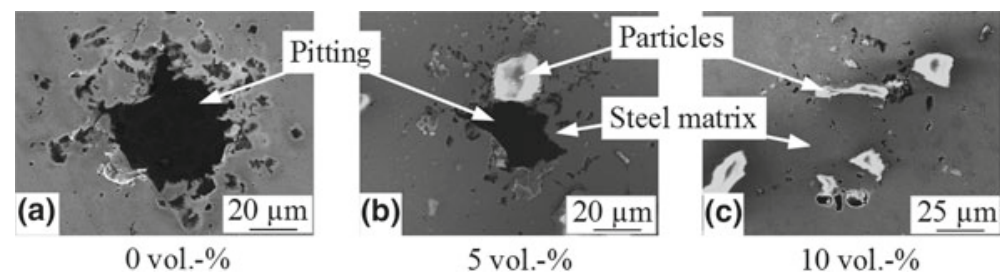

Fig. 17.6 SEM micrographs of the spark plasma sintered Mg-PSZ particle-reinforced steel after polarization in $5 \mathrm{wt} \%$ sodium chloride solution [6]

Fig. 17.7 Content of iron and main alloying elements in the electrolyte after potentiodynamic polarization in $5 \mathrm{wt} \%$ sodium chloride solution [6]

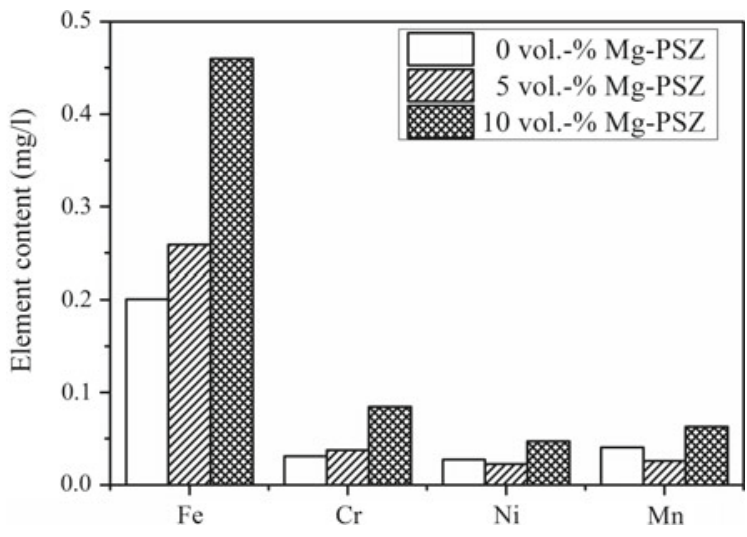


content is increased up to $10 \mathrm{vol} \%$. The electrolyte analysis confirms that the passivation behavior of the steel matrix is drastically reduced when the particle content increases and the entire composite is more susceptible to an aggressive medium.

In a further study, the corrosion behavior of the unreinforced material $(0 \mathrm{vol} \%)$ and the composite with $10 \mathrm{vol} \% \mathrm{Mg}$-PSZ particle content was investigated by a one-year outdoor exposure test and compared to the results obtained after potentiodynamic polarization in a $5 \mathrm{wt} \%$ sodium chloride solution [7]. For the outdoor exposure test, the specimens were stored in an outdoor exposure test rig in Dresden, Germany and sprayed weekly with a $3 \mathrm{wt} \%$ sodium chloride solution.

Figure 17.8 presents the micrographs after the polarization test in the $5 \mathrm{wt} \%$ sodium chloride solution and after the one-year outdoor exposure test.

After polarization, the material without particle reinforcement was attacked by pitting corrosion (I in Fig. 17.8a), whereas the particle-reinforced composite exhibited a uniform corrosion attack and an attack at the particle/matrix interface (II in Fig. 17.8b), which was accompanied by intensified particle detachment (III in Fig. 17.8b). Similar behavior was observed after one year of outdoor exposure testing. Pits were identified on the surface of the unreinforced material (Fig. 17.8c), while a large number of small cavities were found on the composite material that had resulted from the detachment of Mg-PSZ particles (Fig. 17.8d). In addition to these localized corrosion attacks, the intensified formation of red rust was observed. This behavior was more pronounced for the composite material and also confirmed the higher corrosion sensitivity and lower passivation ability that was identified
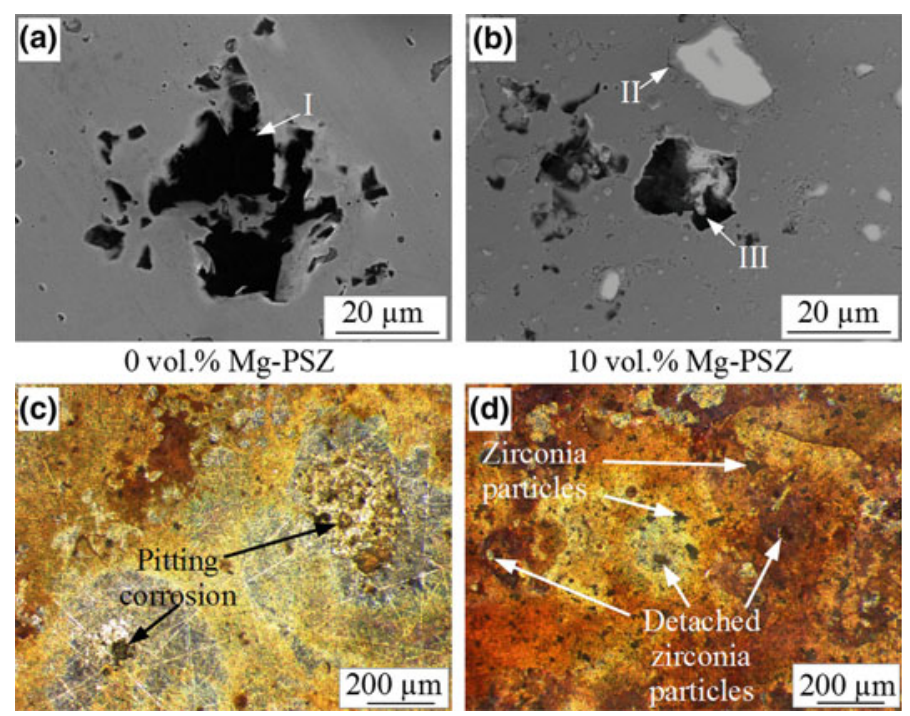

Fig. 17.8 Micrographs of the spark plasma sintered high-alloy steel after potentiodynamic polarization in $5 \mathrm{wt} \%$ sodium chloride solution and after one year of outdoor exposure. $\mathbf{a}$ and $\mathbf{c}$ without particle reinforcement. b and $\mathbf{c}$ with $10 \mathrm{vol} \% \mathrm{Mg}$-PSZ. For I, II and III, see text [7] 
during the polarization test. The results of the study show that under similar conditions, the results of the short-time polarization test can be used to approximate the corrosion behavior associated with long-term outdoor exposure tests.

\subsection{Electrochemical Corrosion of the Particle-Reinforced High-Alloy Steel at Different Temperatures}

The electrochemical corrosion behavior of the composite material with $10 \mathrm{vol} \% \mathrm{Mg}$ PSZ was investigated in a $5 \mathrm{wt} \%$ sodium chloride solution by cyclic polarization and electrochemical impedance at temperatures of $25,35,45$ and $55{ }^{\circ} \mathrm{C}$. In a separate test, the critical temperature for intensified particle detachment was determined [8]. Figure 17.9 presents the optical micrographs of the composite material in its initial state.

Figure 17.10 shows the impedance spectra at different temperatures before the cyclic polarization, which clearly indicate a strong temperature dependency. In the Nyquist plot (Fig. 17.10a) for each temperature, a simple semi-circle is described by the data points, which indicate the reduction of the charge-transfer resistance when the temperature increases. From the Bode illustrations (Fig. 17.10b, c), one time constant was extracted for each temperature. Figure 17.11 shows the electrode configuration and the equivalent circuit that was used for modeling and curve fitting. The results are summarized in Table 17.4. The parameters $Q$ and $\alpha$ did not depend on the temperature to a significant degree, whereas $R_{\mathrm{t}, \mathrm{bp}}$ declined when the temperature increased, indicating an increase in the charge transfer processes when the temperature increased. Similar behavior was noted for the electrolyte resistance $R_{\mathrm{e}}$, signifying an increase in the conductivity of the test solution. Figure 17.12 presents the cyclic polarization curves for the selected temperatures, which clearly illustrate the significant enhancement of the corrosion kinetics when the temperature rises. The corrosion potentials before ( 1 in Fig. 17.12) and after ( 2 in Fig. 17.12) the polarization process did not exhibit any significant dependency on the temperature, whereas the anodic parts of the curves revealed that there was no passivation and that the slopes

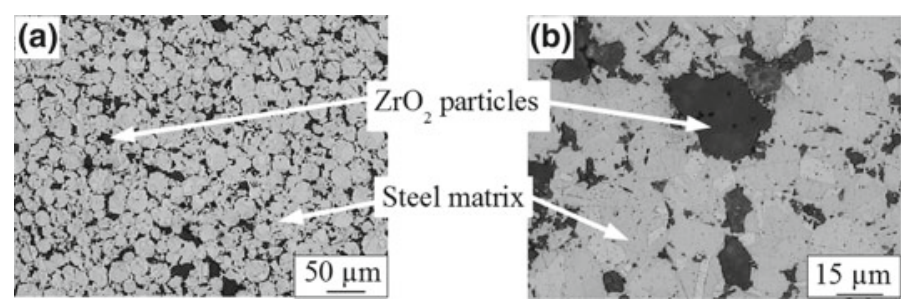

Fig. 17.9 Micrographs of the spark plasma sintered particle-reinforced high-alloy steel with 10 vol\% Mg-PSZ. a Overview of particle distribution in the steel matrix. b Detailed view of particle agglomeration [8] 
Fig. 17.10 Electrochemical impedance spectra of the spark plasma sintered high-alloy steel before cyclic polarization at different temperatures [8]
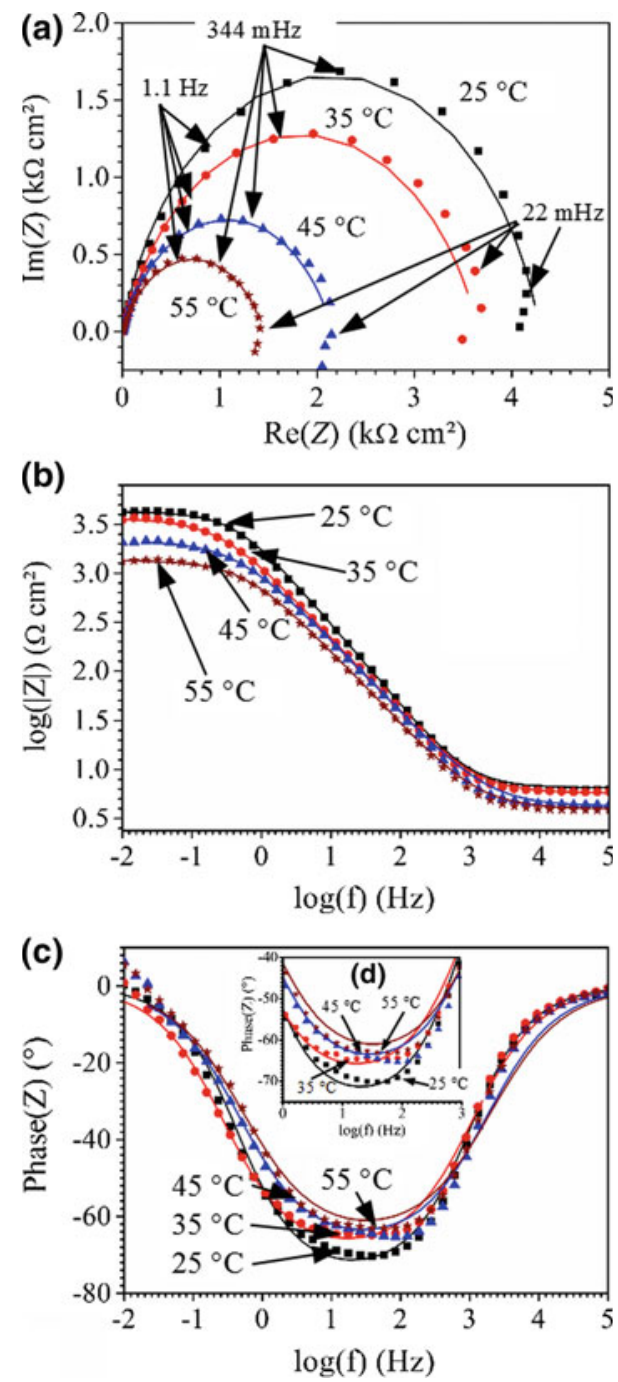

increased in line with the temperature. The more negative values for the corrosion potential 2 in Fig. 17.12 clearly indicated a more corrosion-sensitive electrode state at each temperature after the polarization. From the progression of the curve, it was deduced that the temperature influenced the corrosion potentials minimally, though it affected the polarization behavior significantly. Figure 17.13 shows the electron micrographs of the composite material after cyclic polarization. For 25 and $35{ }^{\circ} \mathrm{C}$, the surfaces showed evidence of a predominantly homogenous corrosion attack with weak localized corrosion attacks (arrows in Fig. 17.13a, b), which were related to the increased porosity due to Mg-PSZ particle detachment. 


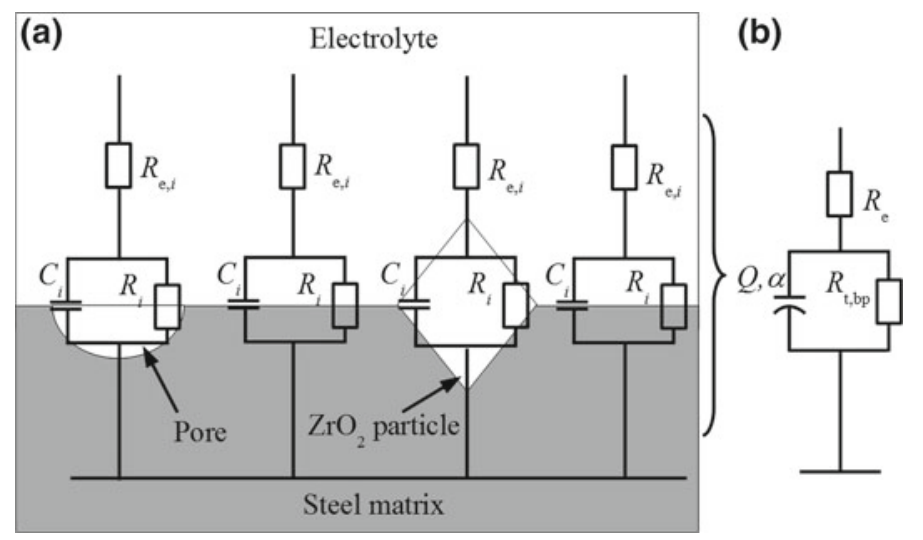

Fig. 17.11 a Schematic illustration of the electrode configuration before cyclic polarization, and b equivalent circuit used for curve fitting. $R_{\mathrm{i}}, C_{\mathrm{i}}$ and $R_{\mathrm{e}, \mathrm{i}}$ stand for the local and $R_{\mathrm{e}}, Q, \alpha$, and $R_{\mathrm{t}, \mathrm{bp}}$ the global impedance parameters before polarization

Table 17.4 Impedance curve fitting results before polarisation in $5 \mathrm{wt} \% \mathrm{NaCl}$ solution on $10 \mathrm{vol} \%$ Mg-PSZ particle-reinforced steel

\begin{tabular}{l|l|l|l|l}
\hline$T\left({ }^{\circ} \mathrm{C}\right)$ & $R_{\mathrm{e}}\left(\Omega \mathrm{cm}^{2}\right)$ & $Q\left(\mu \Omega^{-1} \mathrm{~cm}^{-2} \mathrm{~s}^{\alpha}\right)$ & $\alpha$ & $R_{\mathrm{t}, \mathrm{bp}}\left(\mathrm{k} \Omega \mathrm{cm}^{2}\right)$ \\
\hline 25 & 6.2 & 176 & 0.82 & 4.0 \\
\hline 35 & 5.3 & 302 & 0.74 & 2.1 \\
\hline 45 & 5.0 & 180 & 0.80 & 1.6 \\
\hline 55 & 4.5 & 322 & 0.74 & 1.5 \\
\hline
\end{tabular}

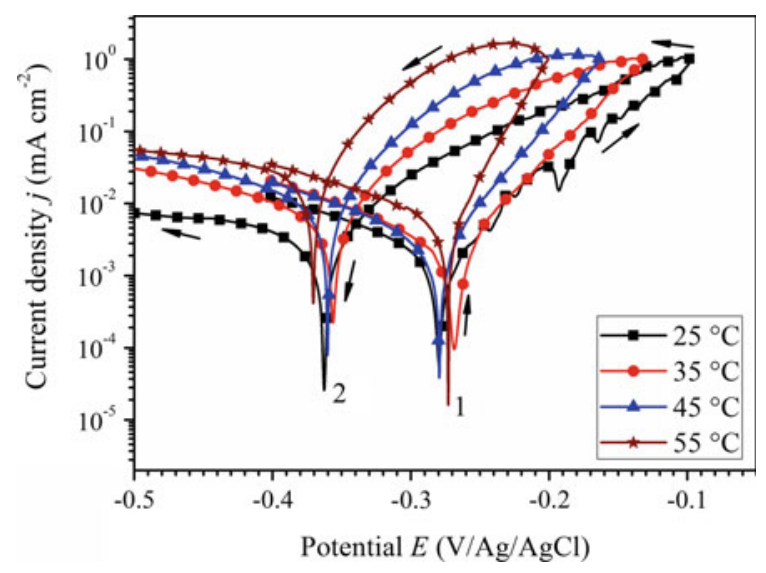

Fig. 17.12 Cyclic polarization curves of the spark plasma sintered particle-reinforced high-alloy steel at different temperatures. $1-E_{\text {Cor }}$ before polarization. 2- $E_{\text {Cor }}$ after polarization [8] 
(a)

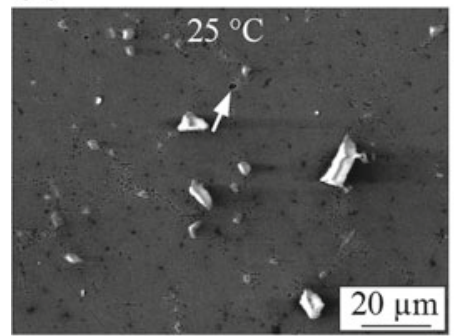

(c)

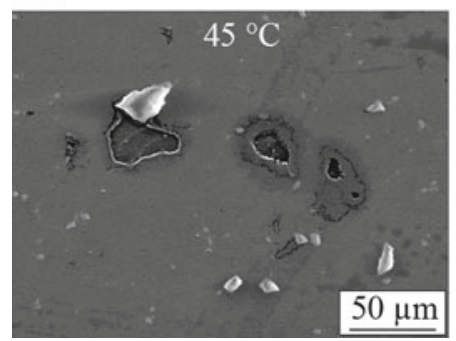

(b)

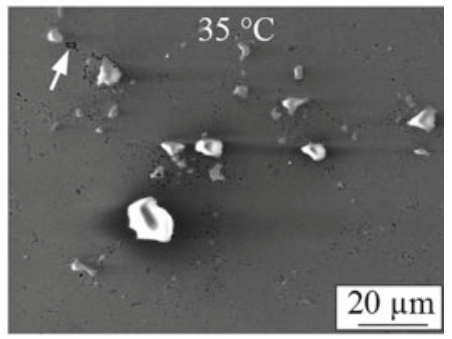

(d)

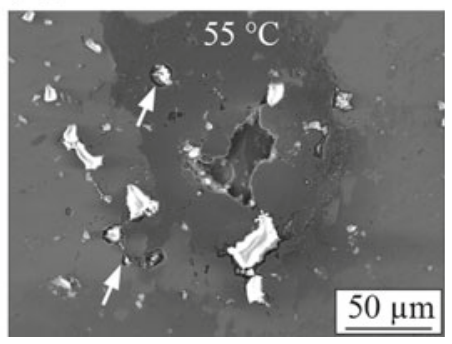

Fig. 17.13 SEM micrographs of the particle-reinforced composite after cyclic polarization in $5 \mathrm{wt} \%$ $\mathrm{NaCl}$ solution at different temperatures [8]

The micrographs observed for 45 and $55{ }^{\circ} \mathrm{C}$ clearly show an attack by localized corrosion that had its origin at the particle/matrix interface (arrows in Fig. 17.13d). It was obvious that when the temperature increased above $35^{\circ} \mathrm{C}$, particle detachment occurred in a more intensified fashion as a result of the enhanced corrosion kinetics at the interface. From the results of the electron microscope observations, it was certain that a critical temperature for intensified particle detachment had to exist in the range of 35 to $45^{\circ} \mathrm{C}$. Figure 17.14 presents the electrochemical impedance spectra measured after the polarization test. Similarly to the initial state shown in Fig. 17.10, the Nyquist illustration revealed a semi-circle for each temperature with a significant decrease of the charge transfer resistance for $T=45^{\circ} \mathrm{C}$ and $T=55^{\circ} \mathrm{C}$ (Fig. 17.14a). From the Bode plots (Fig. 17.14b, c), two time constants were identified for all temperatures, which were related to charge transfer processes at the interface between the composite and the layer generated by film formation and redox reactions inside the film formed. The surface structure and the equivalent circuit used for curve fitting are presented in Fig. 17.15.

After polarization, the global impedance parameters of the composite/film interface were expressed by $Q_{1}, \alpha_{1}$ and $R_{\mathrm{t}, \text { ap }}$ and for the film by $Q_{2}, \alpha_{2}$ and $R_{\mathrm{f}}$. The results obtained by curve fitting are summarized in Table 17.5.

For 25 and $35^{\circ} \mathrm{C}$, the parameters $Q_{1}, \alpha_{1}$ and $R_{\text {t,ap }}$ were dictated by the pores and Mg-PSZ particles. At temperatures of $T=45{ }^{\circ} \mathrm{C}$ and $T=55{ }^{\circ} \mathrm{C}$, the impedance values included the increased porosity, the attacked interface at the particles and the pits that were formed. For the determination of the critical pitting temperature, the 
Fig. 17.14 Electrochemical impedance spectra of the particle-reinforced composite determined after cyclic polarization in $5 \mathrm{wt} \%$ sodium chloride solution for different temperatures [8]
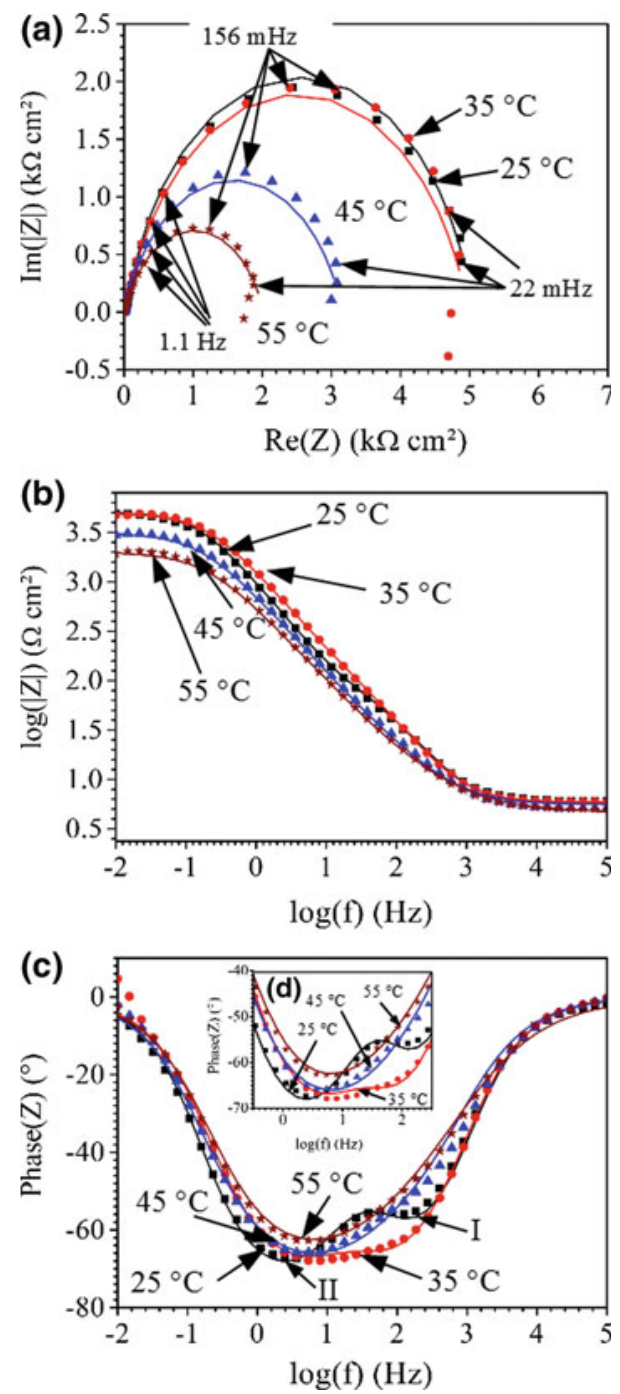

current-time relationship for continuously increasing temperature was recorded, and is shown in Fig. 17.16.

The correlation revealed a slight increase in current density up to a temperature of $34{ }^{\circ} \mathrm{C}$, including a peak between 32 and $33{ }^{\circ} \mathrm{C}$. This characteristic was related to particle detachment. When the temperature increased further, the current density increased significantly and exhibited fluctuations up to a temperature of $38{ }^{\circ} \mathrm{C}-$ which was related to the intensified particle detachment that was evident. For higher temperatures, the current density increased drastically and indicated pitting corrosion 
(a)
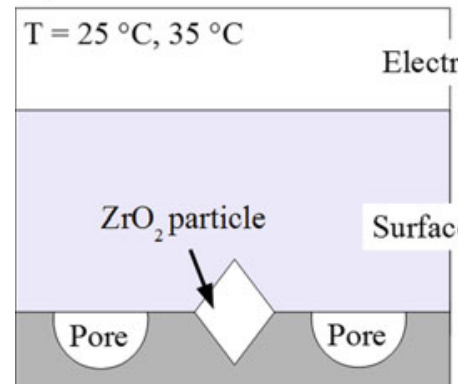

(b)

Electrolyte

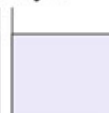

$\mathrm{ZrO}_{2}$ particle attacked

Surface film

Steel matrix

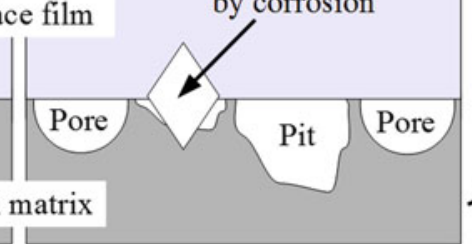

(c)

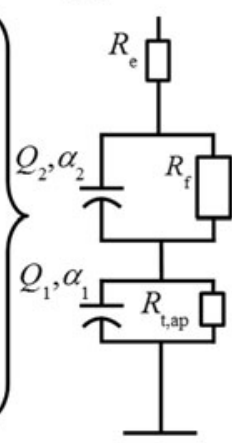

Fig. 17.15 a, b Schematic illustration of the composite interface after polarization in $5 \mathrm{wt} \%$ sodium chloride solution at different temperatures. $\mathbf{c}$ Equivalent circuit used for curve fitting of the impedance spectra [8]

Table 17.5 Impedance curve fitting results after polarisation in $5 \mathrm{wt} \% \mathrm{NaCl}$ solution on $10 \mathrm{vol} \%$ Mg-PSZ particle-reinforced steel. $T$ in ${ }^{\circ} \mathrm{C}, R_{\mathrm{e}}, R_{\mathrm{t}, \text { ap }}$ in $\Omega \mathrm{cm}^{2}$ and $R_{\mathrm{f}}$ in $\mathrm{k} \Omega \mathrm{cm}^{2}, Q_{1}, Q_{2}$ in $\mu \Omega^{-1}$ $\mathrm{cm}^{-2} \mathrm{~s}^{\alpha}$

\begin{tabular}{l|l|l|l|l|l|l|l}
\hline$T$ & $R_{\mathrm{e}}$ & $Q_{1}$ & $\alpha_{1}$ & $R_{\mathrm{t}, \mathrm{ap}}$ & $Q_{2}$ & $\alpha_{2}$ & $R_{\mathrm{f}}$ \\
\hline 25 & 6.3 & 390 & 0.92 & 17 & 215 & 0.83 & 5.4 \\
\hline 35 & 5.5 & 496 & 0.91 & 29 & 64.3 & 0.79 & 4.3 \\
\hline 45 & 5.2 & 229 & 0.77 & 13 & 54.5 & 0.83 & 3.2 \\
\hline 55 & 4.8 & 1260 & 0.58 & 11 & 104 & 0.78 & 1.8 \\
\hline
\end{tabular}

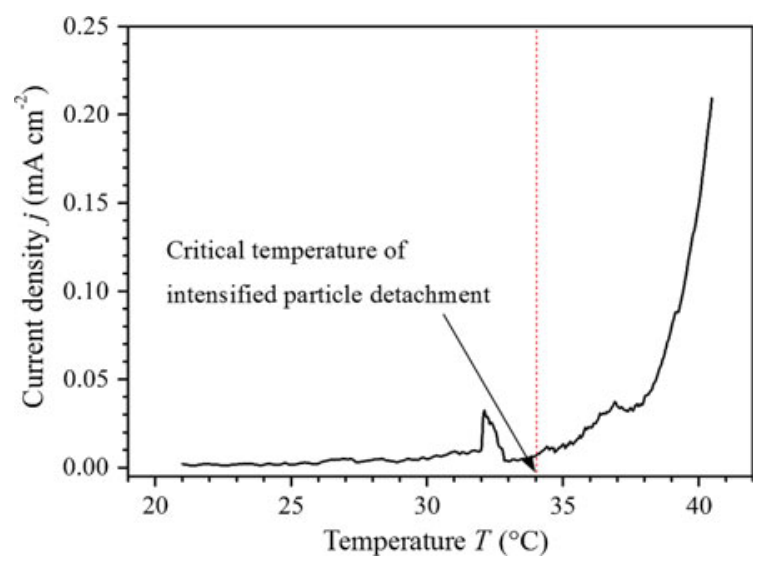

Fig. 17.16 Current density—-temperature relationship for determination of the critical temperature of the composite [8] 
attack. Consequently, the critical temperature for intensified particle detachment and subsequent pitting corrosion attack on the composite was approximately $34^{\circ} \mathrm{C}$.

\subsection{Potentiodynamic Polarization of CastX5CrMnNi16-7-9 in Sulfuric Acid Solution Combined with Acoustic Emission Analysis}

The acoustic emission (AE) technique for the investigation of corrosion phenomena is an excellent method for analyzing the different processes taking place in parallel at the electrode surface $[9,10]$. As shown by Boinet et al. [9], acoustic emission analysis facilitates the separation of surface degradation processes and gas bubble evolution by determination of the frequency of $\mathrm{AE}$ signals. To evaluate the corrosion activity of the high-alloy cast steel CastX5CrMnNi16-7-9 in sulfuric acid solution, the AE method was applied during potentiodynamic polarization. The chemical composition and characteristic microstructure of the initial state are given in Table 17.6 and Fig. 17.17.

In contrast to the widely used two-cell configuration, which is discussed in detail elsewhere [11], the modified test set-up shown in Fig. 17.18 was used, which also facilitated the observation of the gas bubble stream leaving the electrode surface [12].

The polarization characteristic and corresponding $\mathrm{AE}$ activity is presented in Fig. 17.19. To illustrate the correlation between polarization and acoustic emission as well as the involvement of the 30-minute OCP measurement (OCP-open circuit

Table 17.6 Chemical composition of the high-alloy cast steel CastX5CrMnNi16-7-9 in wt\%

\begin{tabular}{l|l|l|l|l|l|l|l|l|l|l}
\hline $\mathrm{C}$ & $\mathrm{N}$ & $\mathrm{Cr}$ & $\mathrm{Mn}$ & $\mathrm{Ni}$ & $\mathrm{Mo}$ & $\mathrm{Al}$ & $\mathrm{Cu}$ & $\mathrm{W}$ & $\mathrm{Si}$ & $\mathrm{Fe}$ \\
\hline 0.048 & 0.076 & 15.7 & 6.29 & 9.23 & 0.082 & 0.047 & 0.011 & 0.02 & 0.853 & Bal. \\
\hline
\end{tabular}

Fig. 17.17 Electron micrograph of CastX5CrMnNi16-7-9 [12]

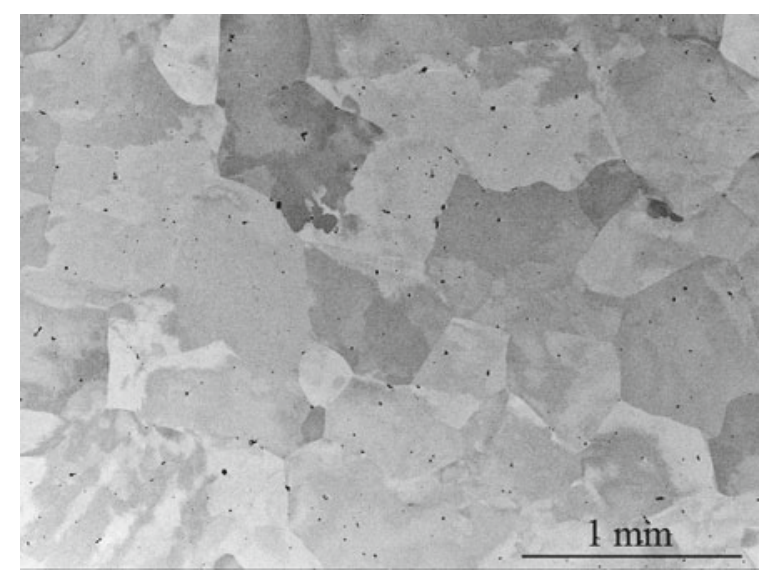




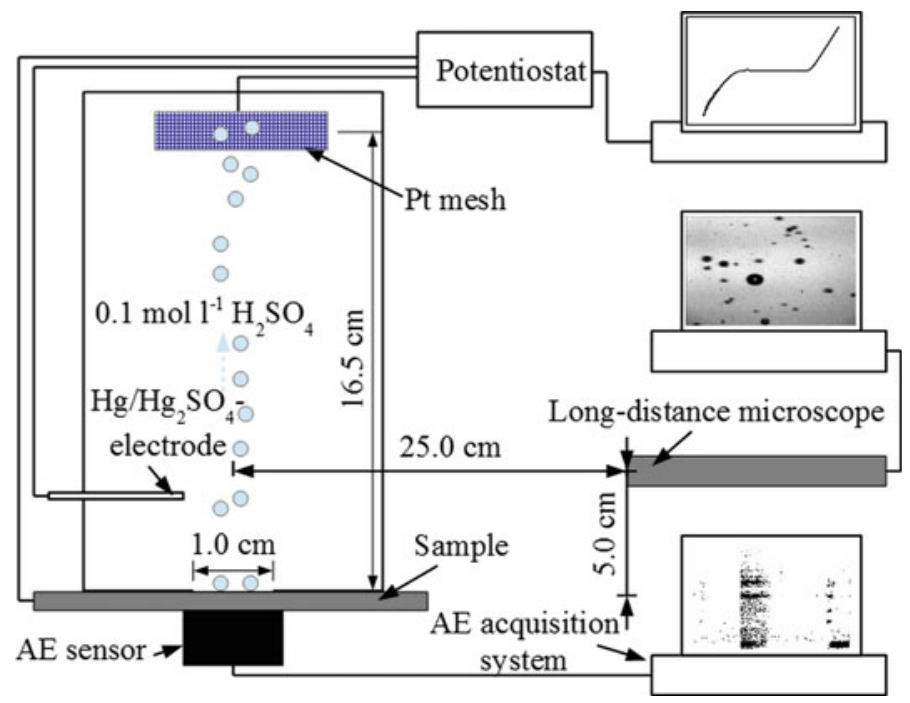

Fig. 17.18 Schematic illustration of the test set-up used for investigation of the acoustic activity and gas bubble evolution process for a steel electrode during potentiodynamic polarization in a $0.1 \mathrm{M} \mathrm{H}_{2} \mathrm{SO}_{4}$ solution [12]

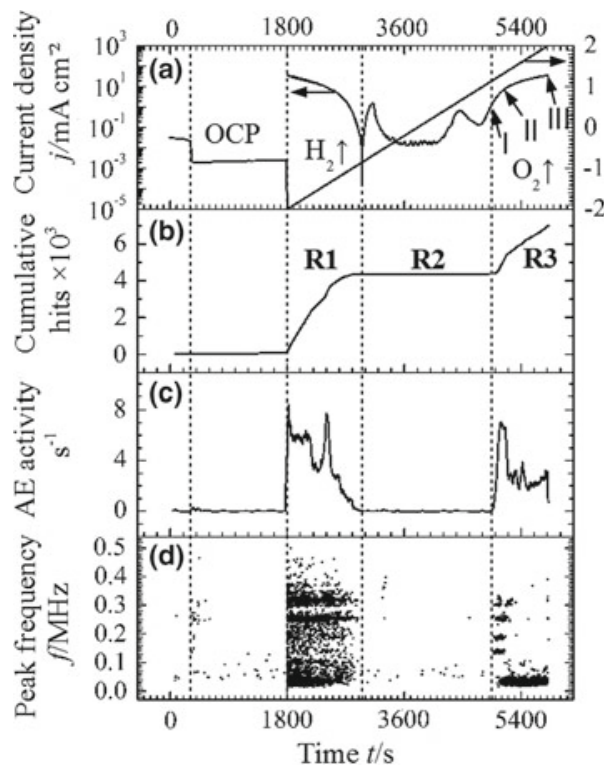

Fig. 17.19 Correlation between the potentiodynamic polarization and measured acoustic emissions. a Open circuit measurement (OCP) and polarization behavior. b Cumulative AE hit number. c AE activity. d Peak frequency of AE signals. I, II and III indicate current densities upon oxygen evolution analysis [12] 
potential), the time $t$ was chosen as the common $x$-axis. In general, 3 regions of acoustic activity (R1, R2 and R3) where recognized during the polarization. Region R1 was indicated by a high level of acoustic activity (Fig. 17.19b, c) and corresponded fully to the cathodic branch of the polarization curve when intensified $\mathrm{H}_{2}$ gas bubble evolution was initiated. Region 2 (R2) was characterized by low AE activity, whereas region 3 (R3) indicated a further increase in acoustic emissions, which was attributed to the evolution of oxygen at the electrode.

Before polarization, the OCP measurement revealed a conspicuous AE event number in the frequency range of $f=150-460 \mathrm{kHz}$ after approximately $t \sim 400 \mathrm{~s}$ (Fig. 17.19d) that corresponded to a significant decline in potential of $\Delta E=570 \mathrm{mV}$ (Fig. 17.19a). The literature indicates that this frequency range is typical for the evolution of a hydrogen bubble at the electrode surface. Consequently, it was concluded that the decline in potential observed indicated the transition of the electrode into the steady state, which was accompanied by the release of hydrogen gas bubbles from the steel surface. The analysis of region 1 (R1) showed the existence of two characteristic processes which occurred almost simultaneously at the steel electrode. One of these was the intensified hydrogen bubble evolution observed during cathodic polarization (see Fig. 17.20a), and generated AE signals in the frequency range of $f=$ $100-430 \mathrm{kHz}$. The hydrogen gas bubbles had a diameter in the range of $200-640 \mu \mathrm{m}$. The second type of AE was observed in the lower frequency range of $f=20-100 \mathrm{kHz}$ and was attributed to the hydrogen-assisted exfoliation process (Fig. 17.20b). The AE data analysis of region R1 revealed two classes of AE signals by determination of its spectral AE energy and signal duration. The results are presented in Fig. 17.20c and clearly show two specific clusters (C1 and $\mathrm{C} 2)$.
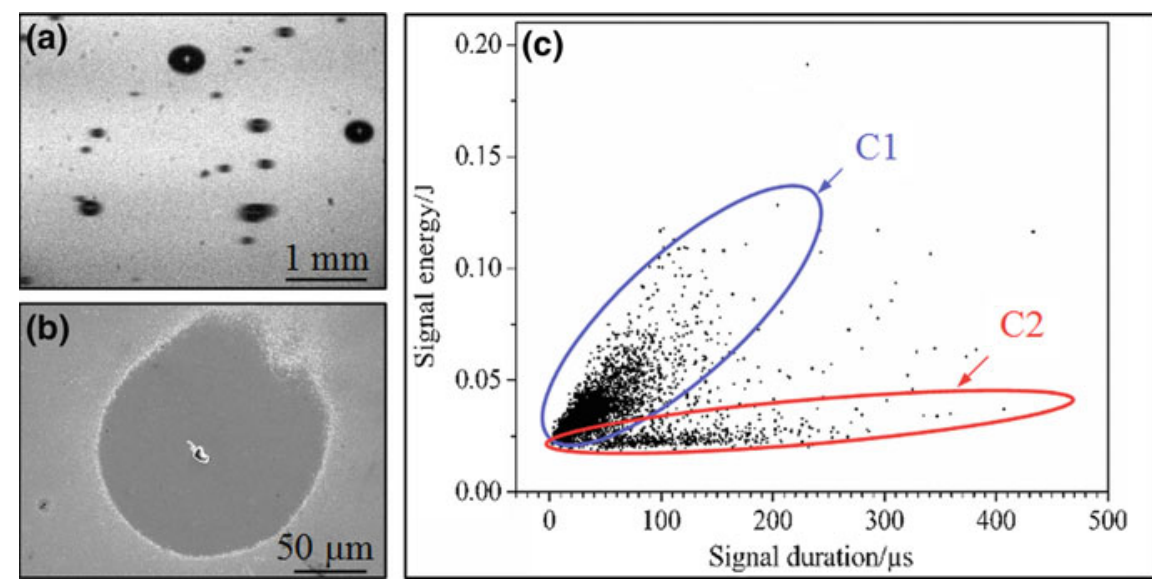

Fig. 17.20 Hydrogen evolution a and hydrogen-assisted exfoliation of the passive oxide $\mathbf{b}$ are the characteristic AE sources during cathodic polarization. The AE data analysis $\mathbf{c}$ indicated a high energy and low duration for the hydrogen bubble evolution process (cluster $\mathrm{C} 1$ ), and low energy with high signal duration for the exfoliation process (cluster C2) [12] 
Cluster C1 was characterized by a high spectral energy and low signal duration and corresponded to hydrogen bubble evolution. In cluster $\mathrm{C} 2$, the signals were typified by lower spectral energies and higher durations, and correlated to the hydrogen-assisted exfoliation process.

At the transition into anodic polarization, the AE hit number and activity (Fig. 17.19 b, c) decreased drastically. Just a low number of AE signals were identified in region $\mathrm{R} 2$, with most of them in the frequency range below $100 \mathrm{kHz}$, which was attributed to electrochemical degradation processes on the steel surface. The surface analysis by SEM identified a corrosion attack at the pore edges (Fig. 17.21) that remained constant when the potential increased within region R2.

Figure 17.22 presents a detailed view of the AE peak frequency characteristics of region R3 (Fig. 17.22a) and the corresponding cluster analysis (Fig. 17.22b). Similar to region $\mathrm{R} 1$, the subsequent $\mathrm{AE}$ data analysis exhibited a high signal energy and low duration for the $\mathrm{AE}$ hits with $f>100 \mathrm{kHz}$ and low energy and high duration for the AE signals with $f<100 \mathrm{kHz}$.

After passing the potential of $E_{1}=1.15 \mathrm{~V}$ versus $\mathrm{Hg} / \mathrm{Hg}_{2} \mathrm{SO}_{4}$, a second increase in $\mathrm{AE}$ activity occurred that correlated with the onset of oxygen gas bubble formation.

(a)

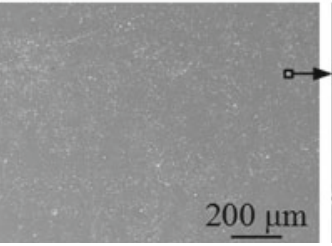

(b)

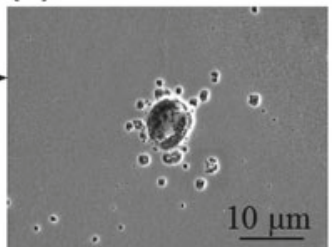

(c)

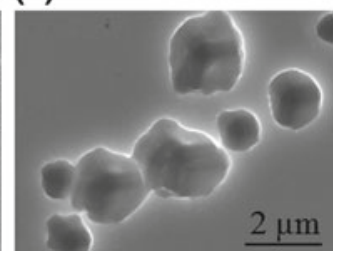

Fig. 17.21 Characteristic damage evolution on the steel surface during anodic polarization in region R2. a Overview. b Detailed view showing corrosion attack at the pore edges. c Detailed view showing corrosion attack at the passive oxide [12]
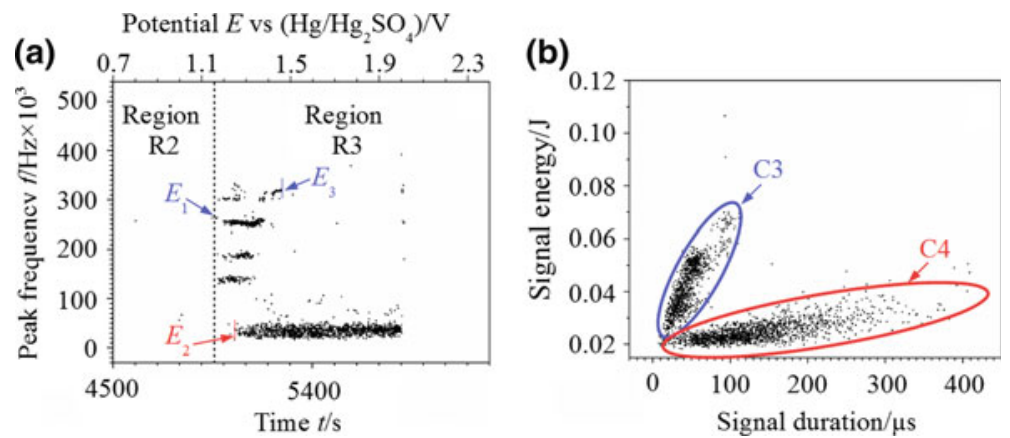

Fig. 17.22 a Observed peak frequency-time relations as a function of the applied potential. $\mathbf{b}$ The corresponding $\mathrm{AE}$ cluster analysis. $E_{1}, E_{2}$ and $E_{3}$ denote the specific potentials of the clusters $\mathrm{C} 3$ and $\mathrm{C} 4$ [12] 
The analysis of the gas stream revealed a bubble diameter in the range of $240-430 \mu \mathrm{m}$ and the AE data exhibited a corresponding peak frequency of $f>100 \mathrm{kHz}$, which was similar to the hydrogen bubble diameter and peak frequency range observed in region R1. Additionally, when the potential was increased further up to $E_{2}=1.25 \mathrm{~V}$ versus $\mathrm{Hg} / \mathrm{Hg}_{2} \mathrm{SO}_{4}$, gas bubbles of significantly lower diameters of approximately $50 \mu \mathrm{m}$ were identified in the gas stream (Fig. 17.23b). Simultaneously, an increase in the number of $\mathrm{AE}$ events within the peak frequency of $f=20-60 \mathrm{kHz}$ was observed (Fig. 17.22a), which was in a similar frequency range to the signals attributed to the hydrogen-assisted exfoliation in region R1 (Fig. 17.19 d). The oxygen gas bubbles with diameters of $240-430 \mu \mathrm{m}$ were designated as oxygen bubbles of Type 1, while the bubbles with a diameter of approx. $50 \mu \mathrm{m}$ were designated as oxygen bubbles of Type 2 .

Moreover, when the potential was increased further up to $E \sim 1.45 \mathrm{~V}$ versus $\mathrm{Hg} / \mathrm{Hg}_{2} \mathrm{SO}_{4}$, the AE signals with a peak frequency of $f>100 \mathrm{kHz}$ ended abruptly, which corresponded well with the disappearance of Type 1 oxygen bubbles in the gas stream. Up to the end of the polarization process, only Type 2 oxygen gas bubbles were identified in the gas stream (Fig. 17.23c).

The damage evolution of the steel surface observed by scanning electron microscopy showed a clearly inhomogeneous corrosion attack (Fig. 17.24a) when the steel was polarized up to point II (II in Fig. 17.19a). In accordance with the observations made after cathodic polarization, pores were the preferred locations for the genesis of Type 1 oxygen gas bubbles (Fig. 17.24b). In addition, the rest of the surface was marked by regions of localized corrosion attacks (F-I in Fig. 17.24c) and areas of full depassivation (F-II in Fig. 17.24c). The drastic increase in damage evolution was attributed to an oxygen-assisted exfoliation process, which identified the steel surface as the location for the formation of Type 2 oxygen gas bubbles. Up to the end of the polarization process (III in Fig. 17.19a), the scanning electron micrographs showed a fully depassivated steel surface and corrosion attack at the grain boundaries due to intergranular corrosion (Fig. 17.24d). As a side effect of the exfoliation process (Fig. 17.24f), a dissolution of the pores was observed that eliminated the basis of Type 1 oxygen bubble evolution (Fig. 17.24e).

Consequently, the rate at which oxygen bubbles was released at the pores had to decrease when the passive oxide dissolution increased. This behavior was in full

(a)

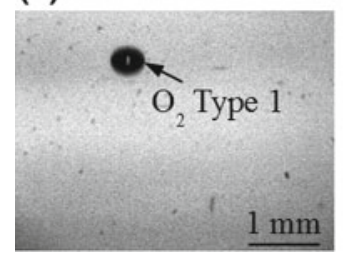

(b)

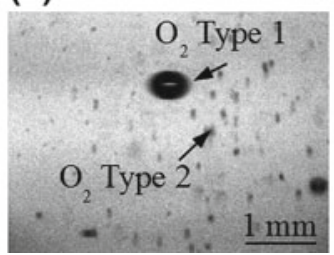

(c)

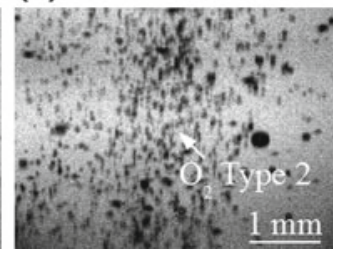

Fig. 17.23 Photographs of the oxygen gas bubble stream at anodic applied potential a at $\mathrm{I}$ in Fig. 17.19a, b at II in Fig. 17.18a, c at the end of the polarization test (III in Fig. 17.19a) [12] 
(a)

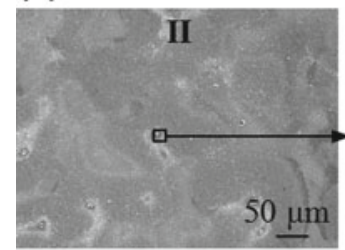

(d)

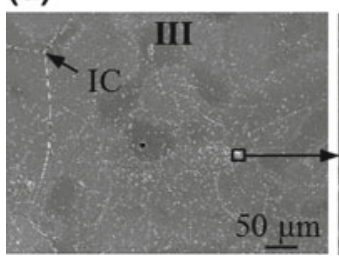

(b)

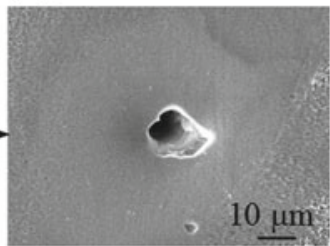

(e)

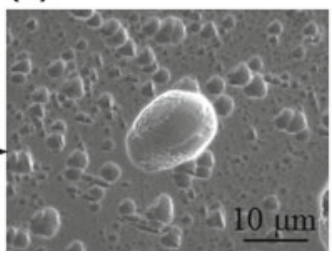

(c)

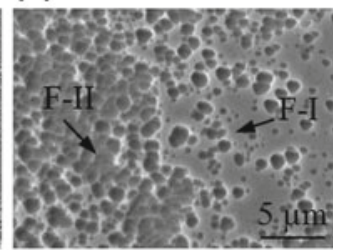

(f)

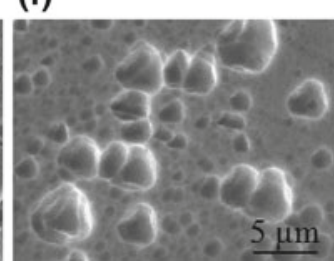

Fig. 17.24 SEM micrographs of the steel surface after polarization up to point II (a-c) and up to the end of the polarization test (d-f). IC-Intergranular corrosion. For F-I and F-II, see text [12]

accordance with the observed decline in the release of Type 1 oxygen bubbles and the identified potential limitation of $\mathrm{AE}$ events with frequencies of $f>100 \mathrm{kHz}$ (Fig. 17.19d).

\subsection{Analysis of Pit Initiation on CastX3CrMnNi16-7-9 by the Combination of Electrochemical Noise and Acoustic Emission Measurement}

The electrochemical noise (EN) and acoustic emission (AE) methods are highly suitable monitoring and analysis tools for the investigation of corrosion initiation processes under steady state conditions [9-17]. The EN technique is based on the measurement of potential and/or current fluctuations, which facilitates the determination of the activity of a corrosion system. The AE technique-based on the measurement of elastic waves-is useful in identifying different corrosion mechanisms occurring at the same time on a surface [12]. One outstanding characteristic is that both methods are non-destructive and highly sensitive, which facilitates the identification of corrosion initiation processes.

Due to these advantageous properties, the EN and $\mathrm{AE}$ techniques were combined in the identification of pit initiation at the surface of the high-alloy cast steel CastX5CrMnNi16-7-9-with the chemical composition and microstructure given in Table 17.6 and Fig. 17.17—in a $5 \mathrm{wt} \%$ sodium chloride solution [18]. The investigation was carried out with the test set-up shown in Fig. 17.25. Details of the experimental specifications of the electrochemical noise and acoustic emission measurements are given in [18]. 


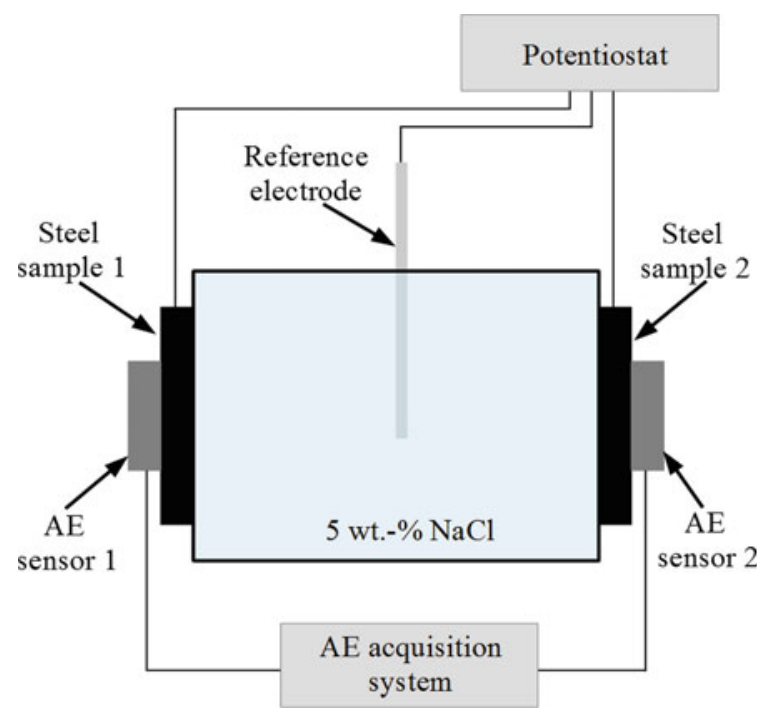

Fig. 17.25 Test set-up used for characterization of the pit initiation behavior of Cast X5CrMnNi167-9 by means of combined electrochemical noise and acoustic emission measurement [18]

Figure 17.26 presents the results of the 70-hour test, which exhibited two characteristic types of AE events and four specific regions of noise behavior. For a more sensitive analysis of the EN behavior, the standard deviations of the potential and current noise $-\sigma_{\mathrm{E}}$ and $\sigma_{\mathrm{i}}-$ were determined and evaluated. The results are shown in Fig. 17.27.

From the point of view of the EN behavior (Fig. 17.27), region EN-I was characterized by strong fluctuations, indicating the high electrochemical activity of the steel surface before transitioning into a nearly steady state after approximately $3 \mathrm{~h}$, which is given by region EN-II. In region EN-II, the signal fluctuations were significantly lower, indicating that the steel surface had transitioned into a passive state. In addition to this predominantly inactive electrochemical state, a spontaneous short-time event was observed after approximately $16 \mathrm{~h}$ of exposure. This event was attributed to localized passive oxide deterioration caused by the chloride ions in the solution, indicating metastable pitting corrosion. Region EN-II ended abruptly after approximately $20 \mathrm{~h}$ of exposure, which was indicated by a drastic increase in potential and current fluctuations that characterized region EN-III. The high degree of fluctuations in region EN-III indicated a highly active surface state. This behavior was related to the onset of an active pitting corrosion attack. Region EN-III had a duration of $15 \mathrm{~h}$ and ended after approximately $35 \mathrm{~h}$ of exposure. The transition into region EN-IV was characterized by a continuous decline in the fluctuations to the point of low electrochemical activity, indicating the repassivation of active pits. Nevertheless, EN-IV also exhibited time intervals of increased activity, which were attributed to a spontaneous and irregular reactivation of previously formed pits and active pit growth. When considering the results of the acoustic emission test, no acoustic activity could 


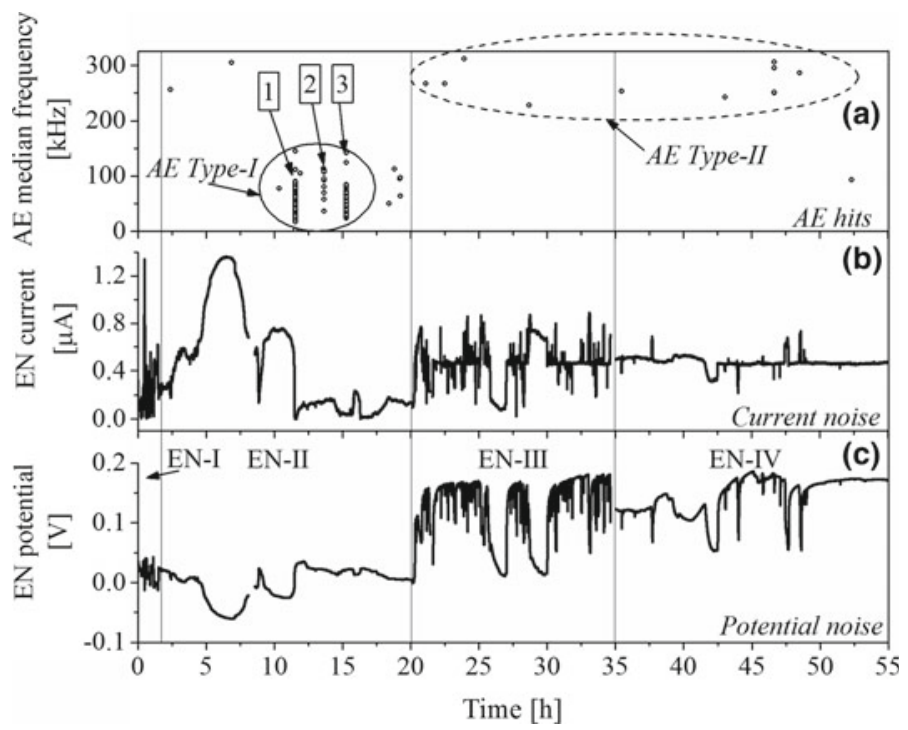

Fig. 17.26 Electrochemical noise behavior and corresponding $\mathrm{AE}$ characteristics of CastX5CrMnNi16-7-9 during a $70 \mathrm{~h}$ exposure test in $5 \mathrm{wt} \% \mathrm{NaCl}$ solution. a Median frequency of the AE signals. $\mathbf{b}$ and $\mathbf{c}$ Current and potential noise signals [18]

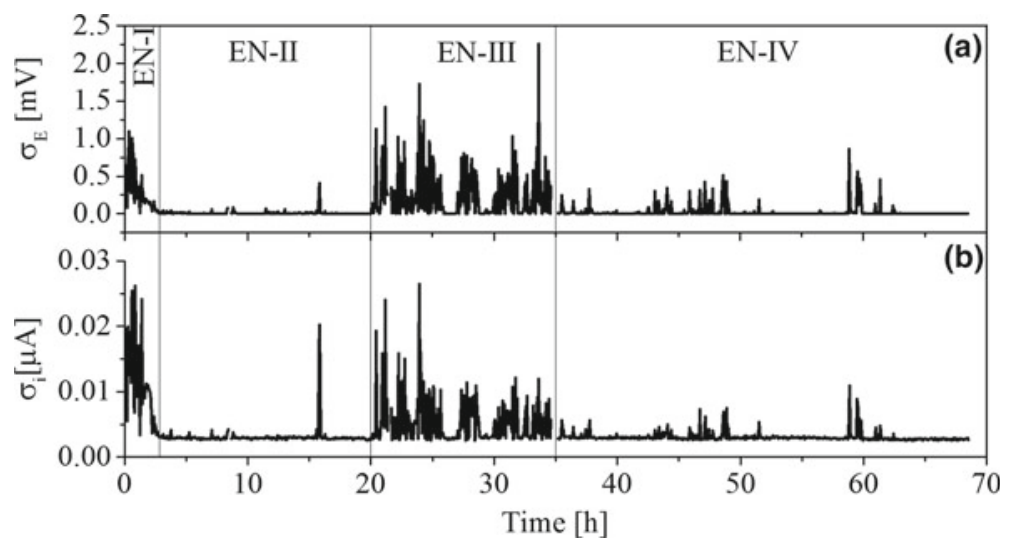

Fig. 17.27 Standard deviation of the potential $\mathbf{a}$ and current $\mathbf{b}$ noise extracted from the signals given in Fig. 17.26b, c [18]

be observed after $10 \mathrm{~h}$ of exposure (see Fig. 17.26a). Indications of AE activity were identified after $t=11.6 \mathrm{~h}, t=13.7 \mathrm{~h}$ and $t=15.3 \mathrm{~h}$, which were marked by the numbers 1, 2 and 3 in Fig. 17.26a and which lay entirely within region EN-II. The events arose in three clusters with a median peak frequency of $f<100 \mathrm{kHz}$, indicating three corrosion attacks at the steel surface. For higher exposure times-especially in the regions EN-III and EN-IV - a second class of events with a median peak frequency 
of $f>100 \mathrm{kHz}$ were observed. The AE signal analysis and the characteristic shape of the waveform (Fig. 17.28) clearly described two different types of AE signals.

The signals with a peak frequency of $f<100 \mathrm{kHz}$ were designated as AE Type I signals and the events with $f>100 \mathrm{kHz}$ were characterized as AE Type II signals (see Fig. 17.26a). With respect to the findings described in the literature [9, 12], it can be stated that AE Type I signals are characteristic for spontaneous and localized passive oxide breakdown, whereas the irregularly distributed events that give rise to AE Type II signals may be attributed to subsequent hydrogen bubble evolution inside previously formed pits $[19,20]$. SEM observations after test completion confirmed localized deterioration in the form of three pits that developed on the steel surface under corrosive attack (Fig. 17.29). Consequently, the electrochemical noise and corresponding acoustic emission development made it possible to identify and follow the point of pit initiation $(t=11.6 \mathrm{~h}$ ) and the subsequent pit evolution process.

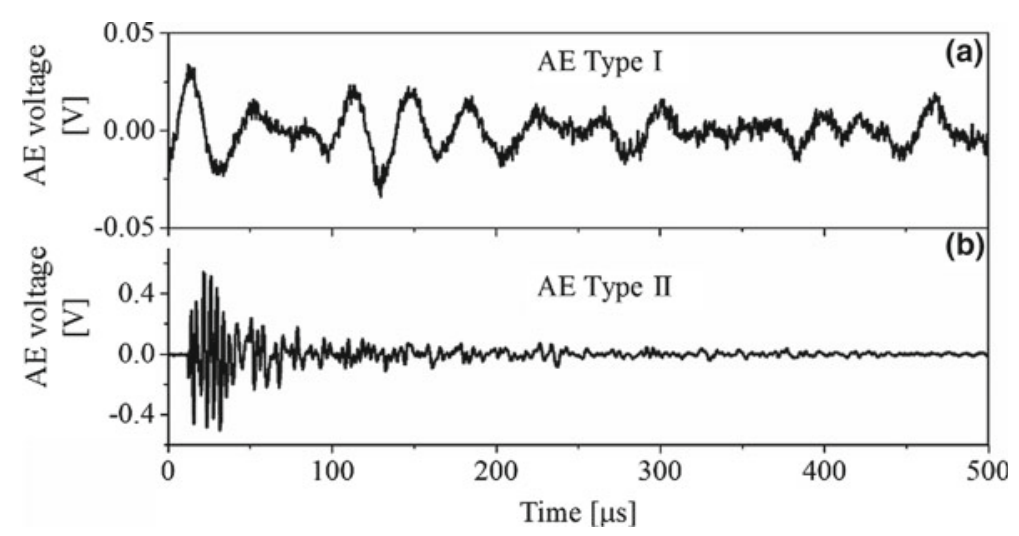

Fig. 17.28 Wave forms of the a AE Type I and b AE Type II signals [18]

(a)

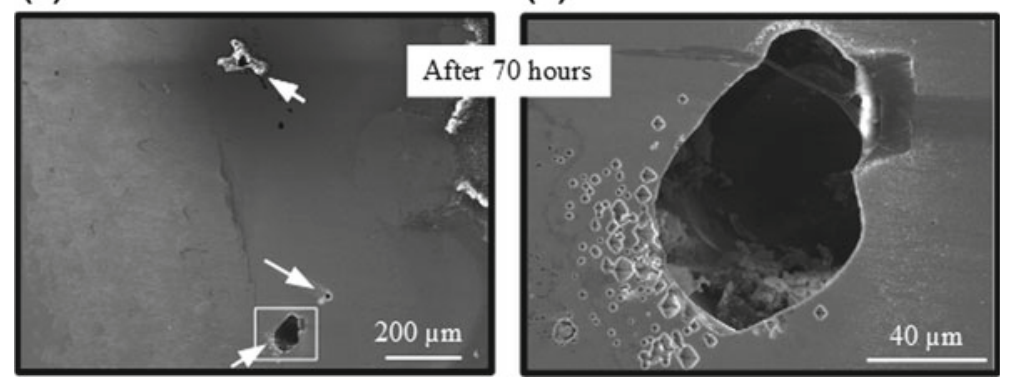

Fig. 17.29 SEM micrograph of the CastX5CrMnNi16-7-9 steel after the $70 \mathrm{~h}$ electrochemical noise and acoustic emission measurement test. a Overview. Arrows indicate the locations of pitting corrosion. b Detailed view of the pit marked with a rectangle in (a) [18] 


\subsection{Analysis of Electrochemical Noise by Continuous Wavelet Transform}

As shown in [18], the electrochemical noise technique is a highly sensitive and, therefore, highly appropriate analysis method for online corrosion monitoring and the identification of different stages in pit evolution. Several techniques in noise data analysis were developed to ensure the precise acquisition of information about the corrosion process. Widely used techniques such as certain statistical methods, the Fourier transformation and wavelet analysis are practiced [14, 21, 22], though highly specified analytical procedures have also been developed to identify and isolate localized and uniform corrosion attacks [23, 24]. In principle, the above-mentioned mathematical techniques analyze the changes in the fluctuations of the noise signal and provide information about the onset, duration and kinetics of a corrosion system [25-27]. A corrosion system that is highly active electrochemically is identified by transients of high frequencies and high amplitudes, whereas a noise signal of lower intensity indicates a more passive corrosion state [14, 28]. Aballe et al. use the discrete wavelet transform (DWT) for subsequent noise data analysis [29, 30], which provides specific information about short-time and long-term corrosion processes. The DWT method was applied for the noise transient analysis of CastX5CrMnNi16-7-9 (with the chemical composition and microstructure presented in Table 17.6 and Fig. 17.17) in sulfuric acid and sodium chloride solutions. In the acid medium, the hydrogen bubble evolution was identified as the process that generated characteristic shorttime corrosion events, whereas long-term transients in the salt-containing solution are characteristic for pit initiation and subsequent evolution processes [17]. As a further method for noise analysis, the continuous wavelet transform (CWT) is used for identification of the dynamic behavior of a system [31]. In consideration of the findings in the literature [21, 29-31], the CWT was applied for the investigation of the noise behavior of the high-alloy cast steel CastX15CrNiMnN19-3-4 (with the chemical composition given in Table 17.7) in sulfuric acid and in sodium chloride solutions, as well as in a combination of both media.

The noise behavior was measured for $2 \mathrm{~h}$ and the corresponding CWT analysis was carried out for a time interval of $20 \mathrm{~min}$ for each system. Figure 17.30 presents the results in a $0.1 \mathrm{M} \mathrm{H}_{2} \mathrm{SO}_{4}$ solution.

The normalized and detrended noise signal exhibited many short-time current transients of high amplitude, indicating a high proportion of corrosion events of short duration. The subsequent CWT analysis exhibited maxima of the CWT coefficients in the upper and middle frequency region between $f=0.063-16 \mathrm{~Hz}$, but with the highest value for the transient after approximately $40 \mathrm{~min}$ (Fig. 17.30a) with $f=4-10 \mathrm{~Hz}$ (marked by the ellipse in Fig. 17.30b). In contrast, the current noise signal for the

Table 17.7 Chemical composition of the CastX15CrMnNiN19-3-4 in wt $\%$

\begin{tabular}{l|l|l|l|l|l|l}
\hline $\mathrm{C}$ & $\mathrm{N}$ & $\mathrm{Cr}$ & $\mathrm{Ni}$ & $\mathrm{Mn}$ & $\mathrm{Si}$ & $\mathrm{Fe}$ \\
\hline 0.148 & 0.165 & 19.1 & 4.12 & 2.85 & 0.5 & Bal. \\
\hline
\end{tabular}


cast steel in sodium chloride solution exhibited significantly less transients of lower amplitude, indicating a system that was less active electrochemically (Fig. 17.31a). The signal analysis exhibited a clear maximum in the lower frequency region with $f=$ $0.063-0.25 \mathrm{~Hz}$ (Fig. 17.31b), which corresponded to the highest transient identified after approximately 6 min of exposure. Figure 17.32a) presents the results of the noise measurement in the mixed electrolyte, which contained identical volume fractions of sulfuric acid and sodium chloride solutions.

The comparison to the results using the unmixed solutions (Figs. 17.31 and 17.32) clearly indicates a drastic increase in the number of transients. The subsequent signal analysis identified maxima in the lower frequency region (with $f=0.016-1 \mathrm{~Hz}$ ) of significantly higher duration, indicating long-lasting corrosion processes in the range of $1 \mathrm{~s}$ to $1 \mathrm{~min}$. The scanning electron micrographs observed after the noise measurements revealed an enhanced intergranular corrosion attack in the unmixed acid solution (Fig. 17.33a) and in the combined electrolyte (Fig. 17.33c). In the sodium chloride solution, the corrosion attack was significantly less. Localized corrosion and the formation of corrosion products arranged in a circle around the pit were observed (Fig. 17.33b), which was a quite different mode of behavior in comparison to that observed in the acid solution.

From the micrographs, it was obvious that the corrosion attack in the unmixed acid and the combined electrolyte was nearly identical. This behavior clearly indicated that the acid dominated the corrosion attack in the combined solution, and that the sodium chloride seemed to have little or no effect on the corrosion attack. When considering the CWT noise analysis, however, the influence of the salt became clear. The
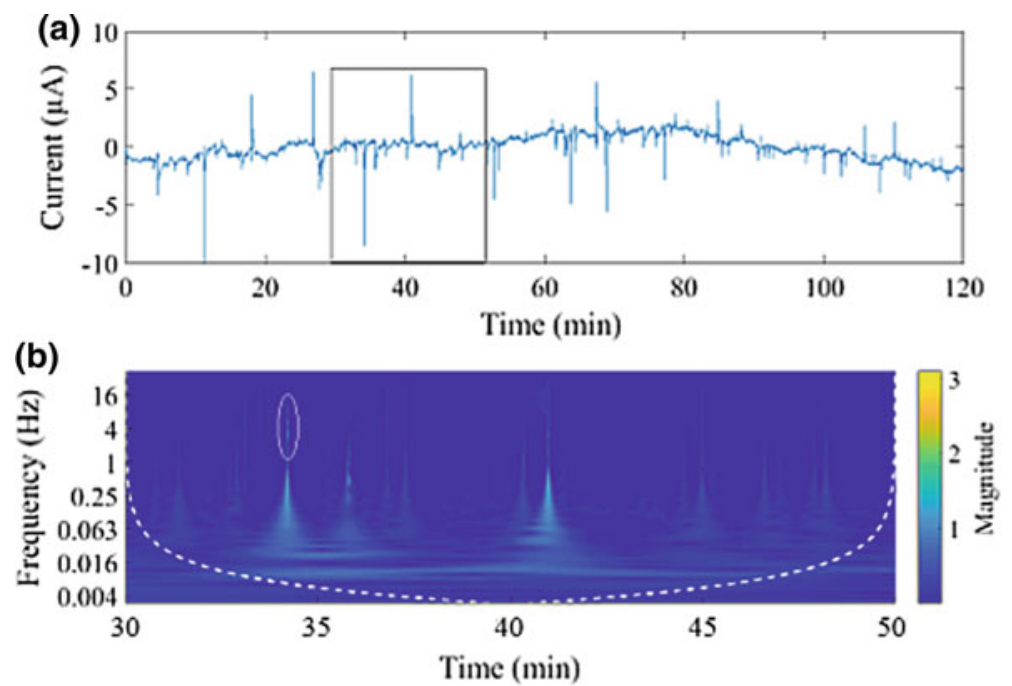

Fig. 17.30 a Current noise-time relation of CastX15CrMnNiN19-3-4 in 0.1 M sulfuric acid solution and $\mathbf{b}$ corresponding CWT analysis of the noise signal for the time interval marked by the rectangle in (a). The ellipse marks the magnitude maximum. Dashed line-the cone of influence 
17 The Corrosion Behavior of High-Alloy CrMnNi Steels ...
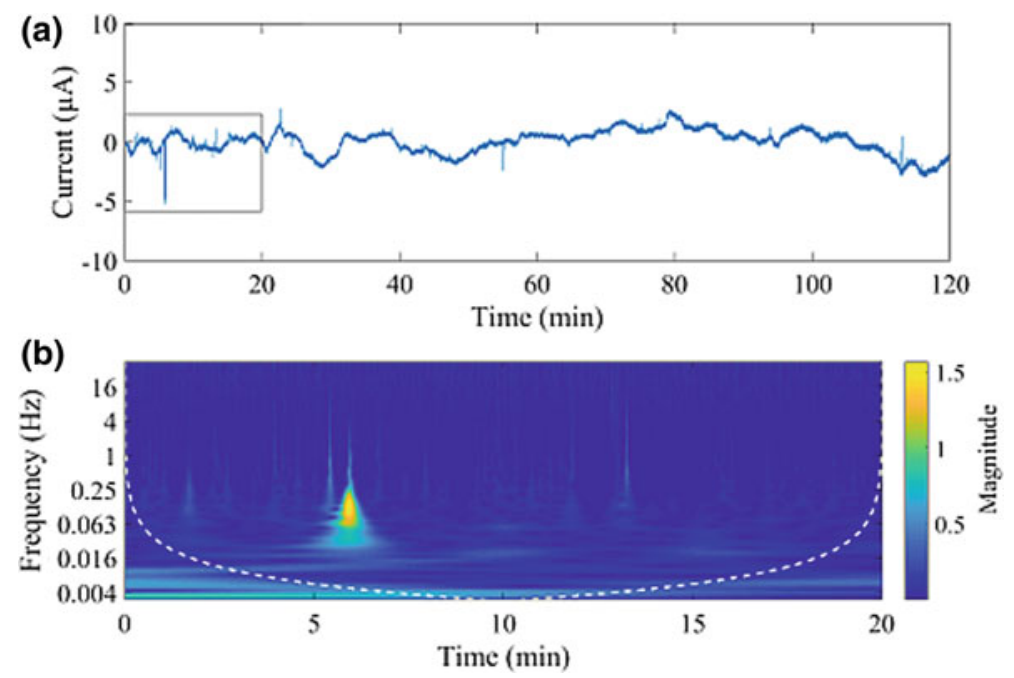

Fig. 17.31 a Current noise-time signal of CastX15CrMnNiN19-3-4 in 5 wt $\%$ sodium chloride solution. b CWT analysis for the time interval marked by the rectangle in (a). Dashed line-the cone of influence
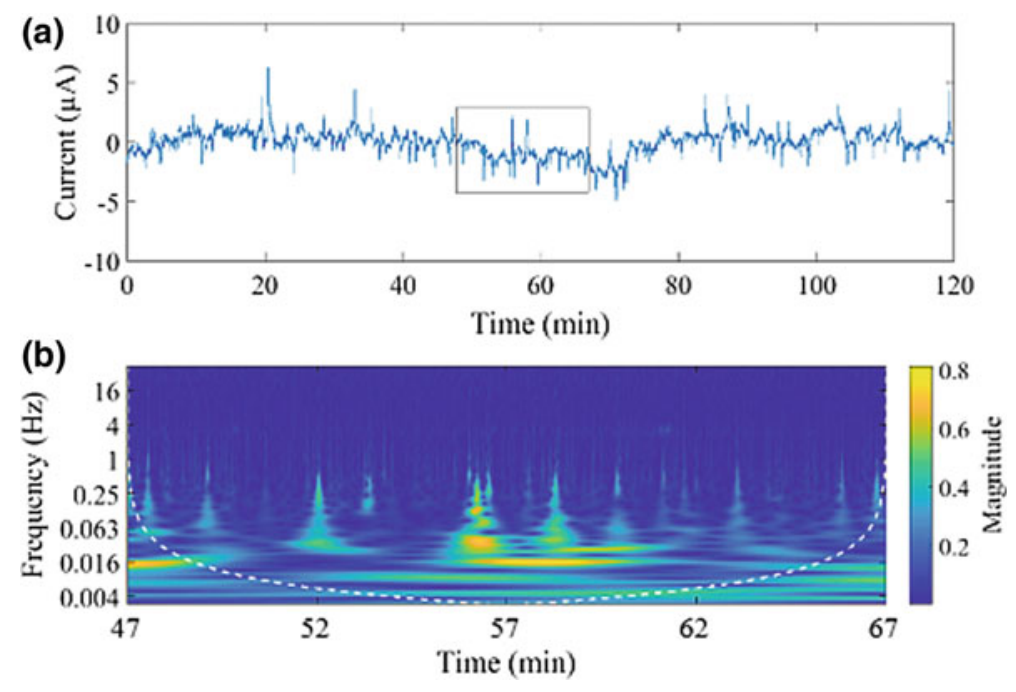

Fig. 17.32 a Noise-time signal of CastX15CrMnNiN19-4-3 in a combined $0.1 \mathrm{M} \mathrm{H}_{2} \mathrm{SO}_{4}+5$ wt $\%$ sodium chloride solution. b Continuous wavelet transform for the time interval marked by the rectangle in (a). Dashed line-the cone of influence 
(a)

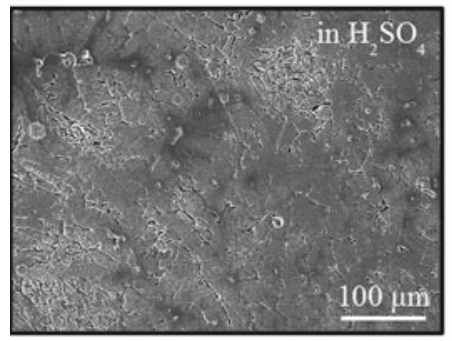

(b)

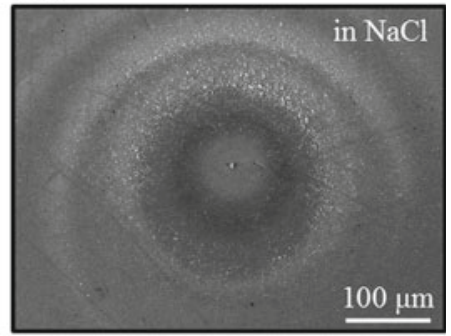

(c)

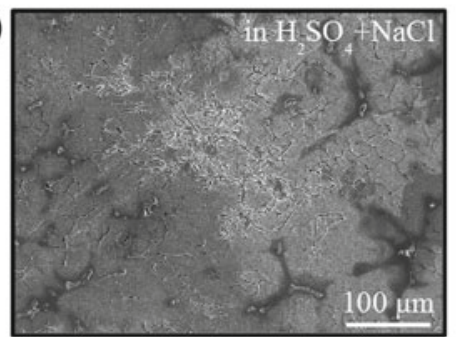

Fig. 17.33 SEM micrographs of the CastX15CrMnNiN19-3-4 after noise measurement in a $0.1 \mathrm{M}$ $\mathrm{H}_{2} \mathrm{SO}_{4}$, b in $5 \mathrm{wt} \% \mathrm{NaCl}$, and $\mathbf{c}$ in $0.1 \mathrm{M} \mathrm{H}_{2} \mathrm{SO}_{4}+5 \mathrm{wt} \% \mathrm{NaCl}$ at a ratio of $1: 1 \mathrm{vol} \%$

maxima in the low-frequency range (Fig. 17.32b) — indicating long-term corrosion processes-indicated a longer-lasting intergranular corrosion attack. Consequently, it was assumed that in the unmixed acid solution, the corrosion attack was characterized by spontaneous active dissolution of the grain boundaries, accompanied by spontaneous repassivation. In the combined electrolyte, the attack also occurred spontaneously, but the repassivation process was drastically hindered, which was predominantly attributed to the $\mathrm{Cl}^{-}$ions.

The study shows the advantage of utilizing electrochemical noise analysis, which facilitated the identification and isolation of short-time and long-term corrosion events simultaneously. In comparison, the effect was not identifiable by SEM observation after a two-hour exposure test.

\subsection{Conclusion}

In this chapter, several studies of the electrochemical corrosion behavior of highalloy cast steels and steel/ceramic composite materials in sulfuric acid and chloride containing aqueous solutions are presented and discussed. For the analysis numerous polarization techniques, outdoor exposure tests and combined methods were carried out. The analyzed characteristics in dependence of applied potential, frequency and temperature give specific information about the influence of the TRIP effect to the corrosion characteristics, were used to design and describe the composite/electrolyte interphase and let extract specific parameters for the evaluation of the pitting 
corrosion sensitivity. Finally, the combination of polarization, electrochemical noise and acoustic emission was used to estimate and separate simultaneous occurring corrosion mechanisms, and more precisely, to identify the time-dependence of specific initiation phenomena and corresponding corrosions damage evolution processes.

Acknowledgements The authors greatly acknowledge the financial support of this works by the Deutsche Forschungsgemeinschaft (DFG, German Research Foundation) as part of the Collaboration Research Centre 799 "TRIP-Matrix Composites" project—Projektnummer 54473466-SFB 799, subproject B6.

\section{References}

1. S. Wolf, S. Martin, L. Krüger, U. Martin, U. Lorenz, Steel Res. Int. 83, 529 (2012)

2. L. Krüger, S. Wolf, S. Martin, U. Martin, A. Jahn, A. Weiß, P.R. Scheller, Steel Res. Int. 82, 1087 (2011)

3. S. Martin, S. Wolf, U. Martin, L. Krüger, D. Rafaja, Metall. Mater. Trans. A 47, 49 (2016)

4. C.-O.A. Olsson, D. Landolt, Electrochim. Acta 48, 1093 (2003)

5. M. Mandel, F. Böhme, M. Hauser, M. Wendler, F. Tuchscheerer, L. Krüger, Steel Res. Int. 87, 1105 (2016)

6. M. Mandel, L. Krüger, S. Decker, Mater. Corros. 66, 1456 (2015)

7. M. Mandel, L. Krüger, S. Decker, Materialwiss. Werktofftech. 46, 1039 (2015)

8. M. Mandel, L. Krüger, S. Decker, Corros. Sci. 90, 323 (2015)

9. M. Boinet, J. Bernard, M. Chatenet, F. Dalard, S. Maximovitch, Electrochim. Acta 55, 3454 (2010)

10. H. Inoue, R. Tsuzuki, S. Nohara, C. Iwakura, Electrochem. Solid-State Lett. 9, A504 (2006)

11. J. Xu, X. Wu, E.-H. Han, Corros. Sci. 53, 448 (2011)

12. M. Mandel, V. Kietov, T. Dubberstein, L. Krüger, Electrochim. Acta 240, 350 (2017)

13. W. Liu, D. Wang, X. Chen, C. Wang, H. Liu, Corros. Sci. 124, 93 (2017)

14. Y. Hou, C. Aldrich, K. Leokova, L.L. Machuca, B. Kinsella, Corros. Sci. 112, 63 (2016)

15. L. Calabrese, L. Bonaccorsi, M. Galeano, E. Proverbio, D. Di Pietro, F. Cappuccini, Corros. Sci. 98, $573(2015)$

16. M. Mandel, W. Kietov, L. Krüger, Defect and Diffusion Forum 367, 42 (2016)

17. M. Mandel, V. Kietov, L. Krüger, Diffusion Foundations 22, 48 (2019)

18. V. Kietov, M. Mandel, L. Krüger, Combination of electrochemical noise and acoustic emission for analysis of the pitting corrosion behavior of an austenitic stainless cast steel. Adv. Eng. Mater. (2018). https://doi.org/10.1002/adem.201800682

19. K. Wu, W.-S. Jung, J.-W. Byeon, Corros. Sci. 105, 8 (2016)

20. C. Jirarungsatian, A. Prateepasen, Corros. Sci. 52, 187 (2010)

21. A. Aballe, M. Bethencourt, F.J. Botana, M. Marcos, J.M. Sánchez-Amaya, Electrochim. Acta 46, $2353(2001)$

22. F.H. Cao, Z. Zhang, J.X. Su, Y.Y. Shi, J.Q. Zhang, Electrochim. Acta. 51, 1359 (2006)

23. A.M. Homborg, E.P.M. van Westing, T. Tinga, X. Zhang, P.J. Oonincx, G.M. Ferrari, J.H.W. de Wit, J.M.C. Mol, Corros. Sci. 66, 97 (2013)

24. A.M. Homborg, R.A. Cottis, J.M.C. Mol, Electrochim. Acta 222, 627 (2016)

25. M.G. Pujar, U. Kamachi Mudali, S. Sekhar Singh, Corros. Sci. 53, 4178 (2011)

26. Y.-J. Tan, N.N. Aung, T. Liu, Corros. Sci. 48, 23 (2006)

27. K. Hladky, J.L. Dawson, Corros. Sci. 21, 317 (1981)

28. B.P. Markhali, R. Naderi, M. Mahdavian, M. Sayebani, S.Y. Arman, Corros. Sci. 75, 269 (2013)

29. A. Aballe, M. Bethencourt, F.J. Botana, M. Marcos, Electrochim. Acta 44, 4805 (1999)

30. A. Aballe, M. Bethencourt, F.J. Botana, M. Marcos, Electrochem. Commun. 1, 266 (1999)

31. P. Montes-García, F. Castellanos, J.A. Vásquez-Feijoo, Corros. Sci. 52, 555 (2010) 
Open Access This chapter is licensed under the terms of the Creative Commons Attribution 4.0 International License (http://creativecommons.org/licenses/by/4.0/), which permits use, sharing, adaptation, distribution and reproduction in any medium or format, as long as you give appropriate credit to the original author(s) and the source, provide a link to the Creative Commons license and indicate if changes were made.

The images or other third party material in this chapter are included in the chapter's Creative Commons license, unless indicated otherwise in a credit line to the material. If material is not included in the chapter's Creative Commons license and your intended use is not permitted by statutory regulation or exceeds the permitted use, you will need to obtain permission directly from the copyright holder.

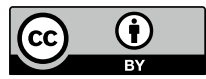

